\title{
Access and use of medicines by elderly individuals with dementia
}

\author{
Débora Santos Lula Barros ${ }^{*}$, Dayde Lane Mendonça da Silva², Silvana Nair Leite
}

${ }^{1}$ Universidade de Brasília, Campus Universitário Darcy Ribeiro, Programa de Pós-graduação em Ciências Farmacêuticas, Brasilia, Brazil, ${ }^{2}$ Universidade de Brasília, Campus Universitário Darcy Ribeiro, Departamento de Farmácia, Brasilia, Brazil, ${ }^{3}$ Universidade Federal de Santa Catarina, Departamento de Ciências Farmacêuticas, Florianópolis, Santa Catarina, Brazil

\begin{abstract}
The objective is to reveal the difficulties concerning the access and use of medicines by elderly individuals with dementia, reported by their caregivers. This qualitative study applied the participant observation method during pharmaceutical appointments performed in a specialized geriatrics service of the University Hospital of Brasília. Caregivers reported facing difficulties regarding the itinerary for medicines access in public pharmacies, as well as the high cost of these technologies in private establishments. Psychiatric symptoms, cognitive deficits, behavioral changes, apraxia, dysphagia, among other clinical manifestations of dementia syndromes, incapacitates the elderly for self-responsibility concerningthe use of drugs, which accentuates the complexity of medicines administration within the care process. In conclusion, it is fundamental to recognize caregivers' role in promoting the rational use of medicines, and so this theme should be highlighted within the pharmaceutical services context.
\end{abstract}

Keywords: Elderly/dementia/care. Caregiver. Drugs/access. Rational use of medicines. Pharmaceutical services.

\section{INTRODUCTION}

The National Policy of the Elderly emphasizes that the presence of a functional disability in this group, regardless the origin of the disability, points to the need for a caregiver (Brasil, 2006). In this context, given the vulnerability situation and the progressive debilitation linked to the illness process, the importance of having a caregiver to elderly individuals with dementia is noteworthy.

In addition to presenting some restrictions due to typical physiological changes of both aging and comorbidities, this special population expresses cognitive deficits, decline in executive functioning, behavioral fluctuations and psychiatric symptoms. Such scenario explains the autonomy loss in the elderly, which consequently leads to dependence on the caregiver so as to perform usual daily living activities, including drug therapy compliance (Floriano et al., 2012; Del Duca, Martinez, Bastos, 2012).

Medicines constitute important health technologies, with multiple purposes as prevention of injuries;

\footnotetext{
*Correspondence: D. S. L. Barros. Programa de Pós-graduação em Ciências Farmacêuticas, Campus Universitário Darcy Ribeiro, Universidade de Brasília, CEP 70910-900 - Brasília. E-mail:debora.farmacia9@gmail.com 6
}

promotion, recovery and rehabilitation of health; and also the use for diagnostic purposes (Vieira, 2007). However, aside from the biomedical universe, medicines fulfill multiple meanings such as "object of adoration and iodine at the same time, the type of relationship that is established when an object is not indifferent" (Banõs-Diéz, FarréAlbaladejo, 2002, p.272). Thus, medicines use acquires deep social meanings, as it ensures the elderly can live with dignity and quality of life, contributing also to his active aging process and higher life expectancy in the family core. Meanwhile, the symbolic dimension materializes the disease recognition and all responsibilities that the treatment assigns (Leite, Vasconcellos, 2008).

Monteschi, Vedana and Miasso (2010) have conducted a qualitative-quantitative research aiming to verify the degree of knowledge and related difficulties present in the drug therapy of the elderly with bipolar disorder. For this purpose, they interviewed the respective caregivers, who described the following drug therapy problems: patients non-adherence, overload of tasks related to drug therapy, inappropriate or ineffective treatment, concern about access to medicines, and patient's alcohol intake.

Understanding the adversities in the context of elderly individuals with dementia care and recognizing 
the background and experiences of both caregivers and patients compose essential factors to develop resolutive and humanized interventions regarding pharmaceutical services. Contributing to this debate, the present study aimed to reveal the obstacles related to access and use of medicines by elderly individuals with dementia, by their caregivers perspective.

\section{MATERIAL AND METHODS}

There are few studies focusing on understanding the routine of medicines usage in Brazil. Discussions regarding analysis of the dynamics of caregivers who provide home care to the elderly with dementia are even scarcer. In order to triangulate these two themes as the analysis object, we adopted the qualitative methodology in health, to better understand individual or collective meaning of drug therapy from the perspective of this cohort's caregivers (Turato, 2005).

Nogueira-Martins and Bógus (2004) point out that interview, observation, and focus group, are the most employed techniques within qualitative methodology in health researches. Participant observation necessarily implies a long process, both for insertion and for experimentation in the field of research, making it possible to develop exploratory and continuous analysis of the subjects within a given scenario (Valladares, 2007). Thereby, we have selected this method to describe all the study's reports and data. We undertook participant observation for a six-month period (July to December 2013), through pharmaceutical appointments carried at the Multidisciplinar Elderly Center (MEC), located in the University Hospital of Brasília, Federal District.

This center (MEC) represents a reference service in the Federal District regarding the follow-up of elderly people with dementia, especially those diagnosed with Alzheimer's disease. It started to operate in December 2002 and stands out because of its assistance to the elderly being performed in an interdisciplinary and integral care perspective (Barros, 2014).

During the research completion period, the service's multiprofessional team - composed by professionals from the university hospital, besides professors, undergraduate and graduate students from University of Brasilia (UnB) - have counted on specialists of the following areas: Geriatrics, Pharmacy, Dentistry, Social work, Psychology, Nursing, Occupational therapy, and Physical therapy.

To carry out participant observation, we followed Patton's criteria described in the theoretical framework of Nogueira-Martins and Bógus (2004), as follows: i. Researcher ability to insert into the research environment (successive visits to the setting before the study period); ii. Interpersonal skills (incorporation and participation of the researcher in the care provided by the different team areas, articulating interpersonal relationships and socio-cultural insertion with professionals and users); and iii. Criteria and means for selecting the material to be registered (through a registration instrument based on field diary structure, as well as recording the pharmaceutical appointments' audios).

Data were collected and recorded exclusively by the principal researcher, and pharmaceutical appointments were performed by a professor from UnB Pharmacy Faculty. This aimed to track patients with drug therapy issues and who should therefore be assisted by the multiprofessional team in a singular and integral way. Along these appointments, researcher has inquired participants about pertinent informations, seeking for an opportune moment to ask the survey questions. At this time, caregivers' reports were explored so as to investigate the difficulties considering access and use of medicines by elderly individuals with dementia.

In addition to the researcher and the teacher, there were also in the appointment room two or three interns from the Pharmacy Faculty, as well as the elderly and his caregivers. Sometimes, information of up to four different caregivers were obtained in a single consultation. Study's inclusion criteria included the following requirements: to be a caregiver of the elderly with a diagnosis of dementia; to be 18 years of age or older; and to be responsible for the correspondent medicines acquisition or administration. There was one patient whose diagnosis changed from Alzheimer's disease to depression throughout the research period, for this reason her caregiver's report was excluded from the study.

Information registered during data collection were transcribed and analyzed according to thematic analysis' technique. Ideas within the statements of participants' discourses originated the study units of meaning, which were organized by two researchers (experts in qualitative research) into categories of analysis, according to Oliveira's study (2008).

This study was approved by the Research Ethics Committee of the Faculty of Health Sciences of University of Brasilia (protocol number 330.999), in accordance with Brazilian regulatory entities.

\section{RESULTS AND DISCUSSION}

Thirty-two pharmaceutical appointments were followed-up, totalizing 44 caregivers reports (more than one caregiver per patient). The sample description is 
shown in Table I. Most caregivers were female $(\mathrm{n}=36$; $81.0 \%)$, were in the $40-59$ age group $(n=21 ; 47.7 \%)$, and were closely related to the patient (son or daughter) $(\mathrm{n}=30 ; 68.1 \%)$, similar data when compared to other studies embracing the elderly caregivers (Babarro et al., 2004; Brodaty, 2009; Gaioli, Furegato, Santos, 2012).

The majority of respondents were classified as informal caregivers $(\mathrm{n}=38 ; 86.4 \%)$. In this category, we included family members who were in some way bonded with the patient, characterized by being, above all, volunteers who performed this function without specific professional training. The other six $(13.6 \%)$ were considered formal caregivers, which means they provided care for the elderly based on their occupation or specific training on caregiving.

Concerns raised by caregivers during pharmaceutical consultations were organized into the following categories of analysis: "access to medicines", "drug therapy accountability ", and "drug therapy administration".

\section{Access to medicines}

According to a national survey on the access, use, and promotion of the rational use of medicines, there have been significant advances in our country's pharmaceutical services scenario (Tavares et al., 2016). Among them, the increasing access to medicines stands out, especially those to treat chronic non-communicable diseases, frequently used by the elderly population.

Despite aforementioned data, and taking into account that this picture does not fit generalizations due to the very nature of this qualitative study, it is not eworthy to consider the still existing access to medicines dilemma that permeates experiences of care. In this sense, caregivers reported the need to arrange exorbitant resources from the family income so as to afford the elderly drug therapy, as it follows:

“...it's getting tough now, this one is very expensive. Last month we spent US\$870.00 and this month we've already spent US\$ 430.00” (caregiver number 3).

This way, although socioeconomic policies have broadened participation of the Brazilian population into the consumer market in recent decades, access to health services and technologies remains unequal, directly affecting the quality of care for the elderly within domiciliary context (Machado, 2013).

Yap, Thirumoorthy and Kwan (2016) pointed the cost of drug therapy as a negative factor for adherence to treatment, particularly for the retired elderly or those with low-income -whose feeding and housing concerns are prior to purchasing medicines. Nonetheless, there are further family expenditures, such as other members' medicines needs, which also burden the budget for the acquisition of health services and technologies. In one of pharmaceutical consultations, when questioned about the elderly's access to medicines, a caregiver reported:

"...well, when it comes to him, I tend to buy it all. We work it out, you know? But mine... The one for osteoporosis is expensive, it's US\$70.00... So we buy just his because it's more serious" (caregiver number 6).

This narrative approaches the discussion of an American study that revealed caregivers usually privilege

TABLE I - Description of caregivers of elderly individuals with dementia assisted by MEC, December 2013

\begin{tabular}{lccc}
\hline Variables & Categories & (n) & $(\mathbf{\% )}$ \\
\hline \multirow{2}{*}{ Gender } & Female & 36 & 81.0 \\
& Male & 8 & 19.0 \\
\hline \multirow{2}{*}{ Age group } & $20-39$ years & 14 & 31.8 \\
& $40-59$ years & 21 & 47.7 \\
& $\geq 60$ years & 9 & 20.5 \\
\hline \multirow{4}{*}{ Caregiver-patient relationship } & Partner & 7 & 15.9 \\
nature & Son / Daughter & 30 & 68.1 \\
& Daughter in law & 1 & 2.3 \\
& Sister & 3 & 6.8 \\
& Grand daughter & 1 & 2.3 \\
& Niece & 1 & 2.3 \\
Caregiver origin & Professional & 1 & 2.3 \\
\hline Total & Formal & 6 & 13.6 \\
\hline
\end{tabular}

MEC: Multiprofessional Elderly Center. 
the acquisition of the elderly treatment, underestimating their [caregivers] own adherence and use of medicines (Shrank et al., 2011).

In order to achieve access to medicines through Brazilian Public Health System (BPHS), caregivers expend multiple efforts in order to accomplish deadlines, to bring all necessary documents, and often to move from one to another establishment of pharmaceutical services network. There was this one caregiver who referred he could not get the elderly medicines in a public community pharmacy due to lack of information:

"We are no longer providing this one. I'll get information on 102 [address of a public establishment named Specialized Component of Pharmaceutical Assistance].... I got to go to HPAP [a mental health specialized hospital], 'cause the doctor told me it was there, but when I got there... They said it's not here, it's on 102. This doctor said it's not, I don't know. So I don't know..." (caregiver number 5).

Thus, health professionals' orientations should also guide patients and their caregivers towards the effective route to access the respective medicines, instructing all about documents, deadlines, and other necessary procedures, according to inherent organizational specificities of each funding component and program concerning the local pharmaceutical services structure.

Access represents a valuable indicator for rational use of medicines (Ferreira et al., 2013). This parameter is likewise closely associated to the satisfaction degree of users with health services, as exemplified in the following speech:

"Galantamine, right? I've already tried to get it with the prescription, I tried it twice. But then the pharmacy attendance passwords end and next time the prescription loses its validity. And it's also not always available [medicines]... Things are pretty difficult at the 'high cost pharmacy' [popular name for public community pharmacies within Specialized Component of Pharmaceutical Assistance context]. I went there about three times and I couldn't get it. If we could, I'd rather not pay. In this case the best to do is just to buy it" (caregiver number 6).

From this caregiver's point of view, his experience was a torment not only because of medicines shortage issue, but also due to the service's operating logistic, which was not able to meet his demands. Ensuring the integrality principle for SUS users contemplates not only the availability of medicines, but is also about instructing them around pharmaceutical services modus operandi, and to promote these health technologies' rational use by the elderly under supervised care.

\section{Drug therapy accountability}

As for the elderly who present limitations in performing instrumental activities of daily living - among which are the ones involving medicines use (Viveiro et al., 2014) - it is crucial that the caregiver takes on the accountability for drug therapy. The elderly's dependence on the caregiver with respect to the drug therapy management is linked, for instance, to memory loss, a common symptom present in dementia syndromes:

"He [referring to the patient] forgot it once [to take the medicines], so the doctor told me to take care of it from now on" (caregiver number 1).

However, these same caregivers complained that all family members should share activities related to medicines use, so that to avoid overload and discontinuity in the care offered to the patient, as it may happen when tasks are strictly assigned to only one individual:

"Look, I can't do it by myself. When I'm home I give him the pills. But what about when I'm at work? The guys occasionally give it, but yet complain" (caregiver number 21).

This approach highlights the need to enhance and strengthen the support network offered to the elderly, so that all caregivers embrace the assignments related to patient's drug therapy, and lead them in a coherent way to reflect a collaborative, effective and safe management.

Considering the opposite circumstance, where caregivers were sharing the responsibility for drug therapy, new barriers emerged. The advantage of the main caregiver being less exposed to exhaustion in this situation is remarkable, since there is collaboration of other individuals in the process of care involving the use of medicines (Vieira et al., 2011). However, in some cases, the elderly may receive care differently by each caregiver given the absence of conduct standards, as observed in this interviewee's report when asked about episodes involving missing doses:

"At first, yes. He had gone to one's place at the weekend, so he forgot about it in the morning and took it at night, when he was back home" (caregiver number 2).

This way, even though health services empower the main caregiver in relation to safe and effective drug therapy management, it is vital that this protagonist disseminates acquired knowledge to all who will take part in the care, so as to ensure the quality throughout the process.

The deficit in the level of self-awareness of disease, a phenomenon known as anosognosia, was recognized as a dementia syndromes' typical symptom (Maki, Yamaguch, Yamaguch, 2013). In this context, the elderly individual 
is not certain about diseases limitations and signs (Sousa et al., 2011), lacking therefore the perception of the need for treatment, as follows:

"He [referring to the patient] no longer takes the medicine, he thinks he doesn't need to... He forgot having labyrinthitis and stopped taking it. And when we say he must take it he says he has nothing. Sometimes he remembers having the disease, sometimes not" (caregiver number 25).

Thereby, besides tensing up family relationship once patients with anosognosia are not able to identify their disabilities and failures, and generally react in a hostile manner when these are pointed out by family members (Maki, Yamaguch, Yamaguch, 2013) - it was also observed that this same phenomenon expands the need of caregivers to be responsible for the care and use of medicines by the elderly.

Deficits in cognitive function lead to memory loss in the elderly, reducing the capacity to remember taking the correct doses, and this aspect has already been mentioned in the literature as a limiting factor for treatment adherence (Yap, Thirumoorthy, Kwan, 2016):

"Sometimes she [the elderly] forgets to take the evening dose. Or otherwise, when she says she has already taken, that means she took it twice" (caregiver number 15).

This scenario may expose the elderly both to the risk of ineffectiveness of treatments used for the management of dementia and other diseases, as well as to drug intoxication. In addition to the forgetfulness component, elderly individuals with dementia present significant vulnerabilities that may arise from the complex polypharmacy phenomenon, which endorses the need for accountability by the caregiver (Maher-Júnior et al., 2014):

"Our mom takes lots of pills. Now it's around 20 per day! Can you imagine her, having a weak mind, and still taking it all by herself? "(caregiver number 9).

\section{Drug therapy administration}

Following the elderly diagnosis, family members retrace roles, functions and tasks to conciliate their daily life with the numerous activities regarding care provision. Still, it was observed that some caregivers had difficulties to effectively turn the administration of medicines into a habit (Smith et al., 2017; Aston et al., 2017):

"...Things are complicated because I work and we're still adjusting the medication. You see, for the person who works that is a change... Until you get organized... So right now things are pretty messy" (caregiver number 7).

There were cases in which caregivers could not conciliate formal employment with the care assignment, being common the decision to quit their jobs and abdicate their career so as to fully dedicate themselves to patient's caregiving. This contributes to perpetuate the social stereotype of women as the main care provider (Pegoraro, Caldana, 2008):

"Look, I tried to take care of everything... It was impossible... Imagine having to give 25 pills? Every single day? In addition to baths, food, changing diapers... Sometimes I think: I can't handle it myself. There's no way, I had to stop working..." (caregiver number 18).

About forgetting the dosage regimens, this aspect was also manifested by caregivers:

"Sometimes we forget it, but we don't give it thereafter, we wait for the next scheduled dose" (caregiver number 25); "Oh yeah! Yes she's taking... Hmm ... My brain... Which one is it? Citalopram, risperidone, I forgot... I ended up forgetting because she recently started them, the first pill box has just ended... Sometimes I forget about the medicine, the things..." (caregiver number 37).

Another study also discusses data regarding forgetfulness of medicines administration times by caregivers (Travis, Bethea, Winn, 2000), demonstrating the relevance of the pharmacist in proposing strategies and using resources to reinforce the memory and treatment adherence by these individuals.

Some caregivers mentioned making adjustments to the therapeutic scheme according to their perception of the patient's health condition (Look, Stone, 2017):

"At first the angiologist had also prescribed zolpidem... I think it was a big mistake, imagine a medicine that unbalances one's mind... She just fell off the bed, and you had to hold her. I diluted it and threw it away. I used only one pill" (caregiver number 10); "I've decided on my ownto split it, because it was causing insomnia" (caregiver number 30).

Practices like this, as dose adjustments, suspension, and introduction of medicines - as well as homemade remedies, are recurrent and on one hand may interfere with effectiveness and safety of drug therapy, and so health professionals tend to disapprove them. On the other hand, social anthropological literature conceives the term therapeutic itinerary as individuals or groups' actions towards health recovery, which may mobilize different resources, including homemade remedies (Cabral et al., 2011). The literature already addresses the theme of selfadjustment of drug therapy by patients (Waheedi et al., 2017; Kobue, Moch, Watermeyer, 2017, Laue, Melbye, Risør, 2017). However, few discussions address how this phenomenon occurs from caregivers perspective, which reinforces the importance of this study results. 
Psychiatric and behavioral symptoms related to clinical manifestation of dementia may increase the elderly intransigence at medicines administration moment (Gillespie et al., 2014):

"To take the medicine? He doesn't want to, he doesn't accept it. I put into his mouth but he holds it in his tooth. Then he says it's gone. He has no difficulty in swallowing food, he 's just not accepting it" (caregiver number 9).

This complexity in adherence to drug treatment concerning the mental health field has been discussed in a study, evidencing that patient resistance results in abnormal medicines use (Cardoso, Galera, 2009). Consequently, the elderly's health state may be impaired, exacerbating symptoms and recurrent hospital admissions.

Regarding parenteral pharmaceutical formulations, apraxia and painful perception related to the procedure constitute obstacles in administering these medicines in the elderly (Travis, Bethea, Winn, 2000):

"...He [referring to the patient] must take both $\mathrm{NPH}$ and regular insulin. But he can no longer do the procedure by himself, and so I have to prick his skin. Even so, he complains that it hurts and doesn't tolerate it. Sometimes he gets angry at me, like it's my fault" (caregiver number 8).

As a result, it is common for the elderly to become apprehensive by the time of the administration, especially with the assigned caregiver.

Behavioral changes of the elderly impair their social life, mostly with family members who are more engaged to the care. The patient may behavior aggressively towards the caregiver (verbally or even physically), and this violence frame may get broader meanings that gradually deteriorate affective relationships. Patient's violent attitude due to a disease can even reach the dimension of symbolic violence, in which the caregiver, over a dominant position within care relationship, legitimizes hostile acts in response to that initial impulse triggered by the elderly. A caregiver who referred to increase the sedative doses in an attempt to minimize interaction with the patient, thus mitigating existent conflicts, elucidates such situation.

Dysphagia is another frequent condition that accentuates the complexity care for the elderly with dementia, owing to the difficulty in swallowing oral medicines and food (Folle, 2012). In order to overcome this obstacle and assure the medicines administration, caregivers perform maceration and grinding of solid forms, which may interfere with biopharmaceutical aspects:

"She can't swallow the pill, it gets stuck in her throat. When it's too big we split it" (caregiver number 11); "I let it in the water until it gets soft" (caregiver number
23); "I crush it and put into water" (caregiver number 24); "I let it dissolving in water" (caregiver number 4).

These strategies may impair the effectiveness and safety of the treatment, and so the pharmacist should plan interventions together with the multiprofessional team in order to select the most suitable pharmaceutical formulations to each patient, adding therefore to the rational use of medicines.

As illustrated, there are several experiences that depict difficulties in access and use of medicines according to the records provided by caregivers of the elderly with dementia. Nevertheless, most caregivers' backgrounds compromise and have intersection with the adherence theme, reinforcing its multifactorial etiology and complexity in the care sphere.

In being responsible for the activities related to promote health and rational use of medicines in the elderly, the caregiver should be singularly reached by pharmaceutical actions involving care. However, it is worth noting the scarcity of studies that address the pharmacist's importance in developing specific communication and interaction skills with caregivers, evidencing the need for further researches in the area.

Several of the abovementioned aspects and discussions were not completely investigated in similar studies, highlighting the importance and depth of our findings. However, it is imperative to expand research in this thematic, once the care dynamics rises new barriers that may hinder the supervision to be performed by the caregiver for elderly individuals with dementia.

\section{REFERENCES}

Aston L, Hilton A, Moutela T, Shaw R, Maidment I. Exploring the evidence base for how people with dementia and their informal carers manage their medication in the community: a mixed studies review. BMC Geriatrics. 2017;17:242.

Babarro A, Garrido BA, Díaz PA, Casquero RR, Riera PM. Profile and burden of care in caregivers of patients with dementia included in the ALOIS program. AtenPrimaria. 2004;15;33(2):61-6.

Banõs-Diéz JE, Farré-Albaladejo M. Aspectos sociológicos delempleo de medicamentos. In: Princípios de Farmacologia Clínica. Barcelona: Masson; 2002.p.271-81.

Barros DSL. A conduta do tratamento medicamentoso por cuidadores de idosos com demência [dissertação]. Brasília: Universidade de Brasília; 2014. 
Brasil. Portaria n ${ }^{0} 2.528$, de 19 de outubro de 2006. Política Nacional da Pessoa Idosa. [acesso 22 jan 2016]. Disponívelem:http://www.saudeidoso.icict.fiocruz.br/pdf/ PoliticaNacionaldeSaudedaPessoaIdosa.pdf.

Brodaty H. Family caregivers of people with dementia. DialoguesClinNeurosci. 2009;11(2):217-28.

Cabral ALLV, Martinez-Hemaez A, Andrade EIG, Cherchiglia ML. Itinerários terapêuticos: o estado da arte da produção científica no Brasil.CiencSaudeColetiva. 2011;16(11):4433-42.

Cardoso L, Galera SAF. Mental patients and their compliance profile to psychopharmacological treatment. RevEscEnferm USP.2009;43(1):161-7.

Del Duca GF, Martinez AD, Bastos GAN. Perfil do idoso dependente de cuidado domiciliar em comunidades de baixo nível socioeconômico de Porto Alegre, Rio Grande do Sul. CienSaudeColetiva. 2012;17(5):1159-65.

Ferreira MBC, Heineck I, Flores LM, Camargo AL, Dal Pizzol TS, Torres ILS, et al. Rational use of medicines: prescribing indicators at different levels of health care. Braz J Pharm Sci. 2013;49(2):329-340.

Floriano LA, Azevedo RCS, Reiners AAO, Sudré MRS. Care performed by family caregivers to dependent elderly, at home, within the context of the Family Health strategy. Texto Contexto Enferm. 2012;21(3);543-8.

Folle AD. A representação social da demência para familiares de pacientes [dissertação]. Brasília: Universidade de Brasília; 2012.

Gaioli CCLO, Furegato ARF, Santos JLF. Perfil de cuidadores de idosos com doença de alzheimer associado à resiliência. Texto Contexto Enferm. 2012;21(2):150-7.

Gillespie R, Mullan J, Harrison L. Managing medications: the role of informal caregivers of older adults and people living with dementia. A review of the literature. J Clin Nurs. 2014;23(2324):3296-308.

Kobue B, Moch S, Watermeyer J. "It's so hard taking pills when you don't know what they're for': a qualitative study of patients' medicine taking behaviours and conceptualisation of medicines in the context of rheumatoid arthritis. BMC Health Services Research. 2017;17:303.
Laue J, Melbye H, Risør MB. Self-treatment of acute exacerbations of chronic obstructive pulmonary disease requires more than symptom recognition - a qualitative study of COPD patients' perspectives on self-treatment. BMC Family Practice. 2017;18:8.

Leite SN, Vanconcellos MPC. Os diversos sentidos presentes no medicamento: elementos para uma reflexão em torno de sua utilização. ArqCatarinenses Med. 2010;39(3):18-23.

Look KA, Stone JA. Medication management activities performed by informal caregivers of older adults. Res Social AdmPharm. 2017;(17):30124-9.

Machado CV. Sobre os rumos das políticas sociais e de saúde no Brasil pós 1988. CadSaude Pub. 2013;29(10):1950-1.

Monteschi M, Vedana KGG, Miasso AI. Terapêutica medicamentosa: conhecimento e dificuldades de familiares de pessoas idosas com transtorno afetivo bipolar. Texto Contexto Enferm. 2010;19(4):709-18.

Maher RL, Hanlon JT, Hajjar ER. Clinical consequences of polypharmacy in elderly. Expert Opin Drug Saf. 2014;13(1).

Maki Y, Yamaguchi T, Yamaguchi H. Evaluation of anosognosia in Alzheimer's disease using the Symptoms of Early Dementia-11 Questionnaire (SED-11Q). Dement Geriatr Cogn Dis Extra. 2013;3(1):351-359.

Nogueira-Martins MCF, Bógus CM. Considerações sobre a metodologia qualitativa como recurso para o estudo das ações de humanização em saúde. Saude Soc. 2004;3(3):44-57.

Oliveira DC. Análise de conteúdo temático-categorial: uma proposta de sistematização. RevEnferm UERJ.2008;16(4):56976.

PegoraroRF, CaldanaRHL. Mulheres, loucura e cuidado: a condição da mulher na provisão e demanda por cuidados em saúde mental. Saude Soc. 2008;17(2):82-94.

Shrank WH, Liberman JN, Fischer MA, Kilabuk E, Girdish $\mathrm{C}$, Cutrona $\mathrm{S}$, et al. Are caregivers adherent to their own medications? J Am Pharm Assoc. 2011;51(4):492-8.

Smith D, Lovell J, Weller C, Kennedy B, Winbolt M, Young C, Ibrahim J. A systematic review of medication non-adherence in persons with dementia or cognitive impairment. PLoS ONE. 2017;12(2):e0170651. 
Sousa MFB, Santos RL, Brasil D, Dourado M. Consciência da doença na demência do tipo Alzheimer: uma revisão sistemática de estudos longitudinais. J Bras Psiquiatr. 2011;60(1):50-6.

Tavares NUL, Luiza VL, Oliveira MA, Costa KS, Mengue SS, Arrais PSD, et al. Acesso gratuito a medicamentos para tratamento de doenças crônicas no Brasil. Ver Saude Pub. 2016;50(Supl 2):7S.

Travis SS, Bethea LS, Winn P. Medication administration hassles reported by family caregivers of dependent elderly persons. J Gerontol A Biol Sci Med Sci.2000;55(7):412-17.

Turato ER. Qualitative and quantitative methods in health: definitions, differences and research subjects. Rev Saude Pub. 2005;39(3):507-14.

Valladares L. Os dez mandamentos da observação participante. Rev Bras Cienc Soc. 2007;22(63):153-5.

Vieira FS. Possibilidades de contribuição do farmacêutico para a promoção da saúde. Cienc Saude Coletiva. 2007;12(1):213-20.
Vieira CPB, Fialho AVM, Freitas CHA, Jorge MSB. Práticas do cuidador informal do idoso no domicílio. RevBrasEnferm. 2011;64(3):570-9.

Viveiro LAP, Almeida AS, Meira DM, Lavoura PH, Carmo CM, Silva JM, et al. Declínio de atividades instrumentais de vida diária associado à perdade força de preensão palmar em idosos internados em enfermaria geriátrica. Rev BrasGeriatGerontol. 2014;17(2):235-242.

Yap AF, Thirumoorthy T, Kwan YH. Medication adherence in the elderly. J Clinical Gerontol Geriatr. 2016;7(2):64-7.

Waheedi M, Jeragh-Alhaddad FB, Awad AI, Enlund H. "Patients' understanding is the problem": physicians' views of nonadherence among Arabs with type 2 diabetes. Patient Prefer Adherence. 2017;11:1413-1421.

Received for publication on $05^{\text {th }}$ September 2017 Accepted for publication on $16^{\text {th }}$ April 2018 